\title{
MEX3A promotes the proliferation, migration, and invasion of non-small-cell lung cancer by activating the MEK/ERK pathway.
}

Yao Zhang

China Medical University https://orcid.org/0000-0002-6223-422X

Hongjiu Ren

China Medical University

Bo Zhang

China Medical University

Yitong $\mathrm{Xu}$

China Medical University

Qingfu Zhang

Chian Medical University

Jun Jiang

China Medical University

Muli Wudu

China Medical University

Hongbo Su

China Medical Universtiy

Xizi Jiang

China Medical University

Zongang Liu

China Medical University

\section{Zifang Zou}

China Medical Universtiy

Xueshan Qiu ( $\nabla$ xsqiu@cmu.edu.cn )

Chnia Medical University

\section{Research}

Keywords: MEX3A, non-small-cell lung cancer, MEK/ERK pathway, therapeutic target gene

Posted Date: February 25th, 2020

DOI: https://doi.org/10.21203/rs.2.24545/v1 
License: (c) (i) This work is licensed under a Creative Commons Attribution 4.0 International License. Read Full License 


\section{MEX3A promotes the proliferation, migration, and invasion of non- small-cell lung cancer by activating the MEK/ERK pathway}

1 Yao Zhang ${ }^{1}$, Hongjiu Ren ${ }^{1}$, Bo Zhang ${ }^{1}$, Yitong $\mathbf{X u}^{1}$, Qingfu Zhang ${ }^{1}$, Jun Jiang ${ }^{1}$, Wudumuli ${ }^{1}$,

2 Hongbo Su${ }^{1}$, Xizi Jiang ${ }^{1}$, Zongang $\mathrm{Liu}^{2}$, Zifang Zou ${ }^{3}$, and Xueshan Qiu ${ }^{1, *}$

$3{ }^{1}$ Department of Pathology, First Affiliated Hospital College and Basic Medical Sciences of China

4 Medical University, Shenyang, China

$5 \quad{ }^{2}$ Department of Thoracic Surgery, Shengjing Hospital College of China Medical University,

6 Shenyang, China

$7 \quad{ }^{3}$ Department of Thoracic Surgery, First Affiliated Hospital College of China Medical University,

8 Shenyang, China

9 * Correspondence:

10 Xueshan Qiu

11 xsqiu@cmu.edu.cn

12 Keywords: MEX3A, non-small-cell lung cancer, MEK/ERK pathway, potential therapeutic

13 target gene, biological behavior

14 Abstract

15 Background: Lung cancer is the second most prevalent type of cancer worldwide; however, its death

16 is the highest among all cancers. Previous studies have shown that MEX3A is associated with

17 Argonaute (Ago) and CDX2 proteins, which are important in tumor progression. High expression of 
MEX3A is also known to negatively affect the therapeutic impact of radiotherapy and chemotherapy. Therefore, we investigated the role of MEX3A in non-small cell lung cancer (NSCLC). resection between 2014 and 2019 at the Pathology Archive of the First Affiliated Hospital of China

Methods: Tumor specimens were collected from 87 NSCLC patients who underwent surgical Medical University, and were subsequently used for immunohistochemistry. NSCLC cell lines and normal bronchial epithelial HBE cell line were used to study the effects of MEX3A by utilizing MEX3A-siRNA, MEX3A-plasmids, and the ERK pathway inhibitor U0126. Western blotting, colony formation assays, MTT assays, and Transwell assays with or without Matrigel were performed to explore the impact of MEX3A on NSCLC.

Results: MEX3A protein expression was associated with tumor differentiation $(\mathrm{P}=0.044)$, size ( $\mathrm{P}=0.020)$, lymph node status $(\mathrm{P}=0.001)$, and $\mathrm{p}-\mathrm{TNM}$ stage $(\mathrm{P}=0.009)$ and was preferentially expressed in tumor tissues. MEX3A was found to be localized to the nucleus. The expression level in cancer tissue was significantly higher than that in normal tissue. According to our study, MEX3A was shown to promote the proliferation, migration, and invasion of NSCLC. In addition, MEX3A regulated the expression of P-MEK, P-ERK, CyclinA2, CDK4, CDK6, RhoA and MMP2. The MEK inhibitor U0126 reduced the biological effects of MEX3A, suggesting that MEX3A increases the carcinogenic activity of NSCLC cells through activation of the MEK/ERK signaling pathway.

Conclusion: These results suggest an association between MEX3A expression and the unfavorable clinicopathological characteristics of NSCLC patients. And MEX3A promote NSCLC progression by increasing the proliferative and metastatic potential of cancer cells through upregulation of the MEK/ERK pathway. We propose that MEX3A is a candidate prognostic biomarker and potential therapeutic target in NSCLC.

Keywords: MEX3A, non-small-cell lung cancer, MEK/ERK pathway, therapeutic target gene 
42 Lung cancer is the second most prevalent type of cancer worldwide; however, the death rate of lung

43 cancer is the highest among all cancers. Non-small-cell lung carcinoma (NSCLC) accounts for 85\% $90 \%$ of lung cancer cases (1-3). If surgical resection can be performed in a timely manner, it is the best treatment for NSCLC patients. However, even when patients are treated in time, their long-term

survival rate is not ideal, and many patients will still die from recurrence or metastasis. The prognosis of NSCLC patients is mainly affected by metastasis and is closely related to the transcriptional regulation of key genes (4-6).

The MEX3-family of proteins are translation inhibitors, that are necessary for the recognition and maintenance of germ line stem cells (7). The MEX-3-family has four members encoded by the following genes: $M E X 3 A, M E X 3 B, M E X 3 C$, and $M E X 3 D$, which are located on chromosomes 1q22, 15q25.2, 18q21.1 and 19p13.3, respectively (7). These proteins have two domains: one is a highly conserved RNA-binding domain (KH domain), the other is ring domain with E3 ubiquitin ligase activity located at the C-terminal (8). These four proteins are concentrated primarily in the cytoplasm, and they shuttle between the cytoplasm and nucleus through the CRM1 pathway (9). MEX3D is widely expressed in a variety of tissues, while the other three proteins are differentially expressed depending on tissue-type. MEX3A and MEX3D are components of the RNA granules known as processing bodies (P-bodies) and locate and interact with hDcp1, a decapping factor (7). During the degradation of mRNA, decapitation at the 5 'end is primarily carried out at a specific site in the cytoplasm known as a P-body. MEX3A and MEX3B are related to Argonaute (Ago) (10), of which two domains, PAZ and PIWI, are essential for the interaction between siRNA and target mRNA, leading to the cutting or translation inhibition of target mRNA. MEX3C, an RNA-binding E3 ubiquitin ligase, mediates the decay of post-transfer HLA-A antibodies.(11). In regard to tumors, 
MEX3A is related to the occurrence and development of gastric and colorectal cancer. Moreover,

65 MEX3A has been shown to affect the efficacy of radiotherapy and chemotherapy (12-14).

66 Until now, the relationship between MEX3A and the development of NSCLC has not been studied.

67 Our study is the first to demonstrate the significance of MEX3A in the poor prognosis of NSCLC.

\section{$\begin{array}{lll}68 & 2 & \text { Materials and Methods }\end{array}$}

\subsection{Patients and specimens}

A total of 87 patients with NSCLC documented between 2014 and 2019 in the Pathology Archive of the First Affiliated Hospital of China Medical University were enrolled in our study. These patients were first diagnosed between 2014 and 2019 and underwent surgical resection of tumors. None of the patients underwent radiotherapy or chemotherapy prior to surgical resection. Tumor tissues and corresponding normal adjacent tissues were stored in $-80^{\circ} \mathrm{C}$ prior to analysis.

\subsection{Cell culture}

Along with the tissues obtained from NSCLC patients, we used NSCLC cell lines A549, H1299, H460, H661, SK-MES-1, H226, and H292 (Cell Bank of the China Academy of Sciences, Shanghai, China), and normal bronchial epithelial HBE cell lines A549, 1299, H460, H661, H226 (ATCC : Manassas, VA, USA) cultured with RPIM 1640 medium (Gibco, Waltham, MA, USA). HBE cells were cultured with MEM (Gibco) containing $1.5 \mathrm{~g} / \mathrm{L} \mathrm{NaHCO}_{3}$ and $0.11 \mathrm{~g} / \mathrm{L}$ sodium pyruvate. $\mathrm{HBE}$ and H292 cells were cultured with DMEM (Gibco) containing 1.5g/L NaHCO 3 . All media were supplemented with 10\% qualified fetal bovine serum (FBS15015: Clark Biosciences Richmond, VA, 83 USA).

\subsection{Cell transfection and inhibitor}


Following a $20 \mathrm{~h}$ incubation period, MEX3A-siRNA (Ribobio, Guangzhou, China) and MEX3Aplasmids (GeneCopoeia, USA) were transfected into the cell suspension together with opti-MEM

87 (Gibco, Waltham, MA, USA) and Lipofectamine 3000 (Invitrogen, Waltham, MA, USA) to decrease or increase the expression of MEX3A in NSCLC cells.

89 Cells were treated with $10 \mu \mathrm{M}$ U0126 (MedChemExpress, Monmouth Junction, NJ, USA), an

90 inhibitor that blocks the mitogen-activated protein kinase kinase/extracellular receptor kinase

91 (MEK/ERK) signaling pathway. U0126 was dissolved in dimethyl sulfoxide (DMSO) (10 $\mu \mathrm{M})$ and added for $1 \mathrm{~h}$ after $48 \mathrm{~h}$ transfection, with the same volume of DMSO added to control cells.

\subsection{Immunohistochemistry}

The specimens were fixed in 10\% neutral formalin and embedded in paraffin. Then, the specimens were cut into $4 \mu \mathrm{m}$ thick sections. Immunohistochemistry was performed according to the

streptavidin-peroxidase method. Firstly, the sections were deparaffinized in xylene, and rehydrated in a graded alcohol series for dewaxing. The sections were washed by phosphate-buffered saline (PBS). Then, sections were treated with $0.01 \mathrm{~mol} / \mathrm{L}$ citrate buffer (Maixin-Bio, Fuzhou, China) under high pressure for 3 min. An Elivision Reagent KIT9921 (Maixin, Fuzhou, China) for immunohistochemistry was used according to the manufacturer's instructions. Sections were treated with antibody-MEX3A (1:200 dilution, Sigma, St Louis, MO, USA) for $16 \mathrm{~h}$. The reaction was visualized using the Elivision super HRP (Mouse/Rabbit) IHC Kit (Maixin, Fuzhou, China). The chromogenic reagent was 3'3-diaminobenzidine and the nuclei were identified with hematoxylin (Maixin, Fuzhou, China).

Two investigators, blinded to the clinical data, semi-quantitatively scored all slides by evaluating the staining intensity and percentage of cells stained in representative areas of each slide. The percentages of stained cells were scored as follows: 1 (1\%-25\%), $2(26 \%-50 \%), 3(51 \%-75 \%), 4$ 
108

(76\%-100\%). Based on staining intensity, MEX3A expression was also scored as follows: 0 (no staining), 1 (weak staining), 2 (moderate staining), and 3 (high staining). Percentage scores were assigned as follows $0(0 \%), 1(1 \%-30 \%), 2(31 \%-70 \%)$, and $3(71 \%-100 \%)$. The scores of each tumor sample were multiplied to give a final score ranging from 0 to 9 , with tumor samples scoring $>$ 3 considered MEX3A-high, and those scoring $\leq 3$ considered MEX3A-low.

\subsection{Western Blotting}

The expression of proteins directly influences cell migration and invasion (15-19) as well as cell proliferation and cell cycle progression (20-24). Total cellular or tissue protein was extracted using a lysis buffer (P0013, Beyotime, Biosciences, Shanghai, China) and added into a protease-inhibitor cocktail (B14002, Biotool, Shanghai, China) and phosphatase-inhibitor cocktail (B15002, Biotool). Proteins $(80 \mu \mathrm{g} /$ lane $)$ were separated by sodium dodecyl sulfate-polyacrylamide gel electrophoresis (10\% gels), and were then transferred to polyvinylidene fluoride membranes (Millipore, Billerica, MA, USA), and the membranes were blocked with 5\% skim milk (232100;Becton Dickenson, Franklin Lakes, NJ, USA) in Tris-buffered saline with Tween-20 at room temperature for $1 \mathrm{~h}$. After being treated with the appropriate primary antibodies (Table 1 ) at $4{ }^{\circ} \mathrm{C}$ for $16 \mathrm{~h}$, the proteins were treated with horseradish peroxidase-conjugated anti-mouse/rabbit IgG (1:200, ZSGB-BIO, Beijing, China) at $37^{\circ} \mathrm{C}$ for $1 \mathrm{~h}$. Immune reactivity was detected by enhanced chemiluminescence (Thermo Fisher Scientific, Waltham, MA, USA) using a BioImaging system (UVP, Inc., Upland, CA,USA). Relative protein expression was calculated after normalization to GAPDH or $\beta$-actin used as a loading control. The data were visualized and analyzed in ImageJ software.

\subsection{Cell proliferation and colony formation assays}

Cell proliferation was evaluated daily for 5 days using the colorimetric MTT assay. For this assay, 96-well culture plates were seeded with 3000 cells/100 $\mu \mathrm{L}$ culture medium with $10 \%$ qualified fetal 
131 bovine serum in each well. MTT solution (10 $\mu \mathrm{L} /$ well $)$ was added for $4 \mathrm{~h}$, and then MTT crystals in

132 living cells were solubilized with $100 \mu \mathrm{L}$ DMSO and the optical density was measured at $490 \mathrm{~nm}$

133 using a microplate reader.

134 For colony formation assays, cells were seeded in 6-well culture plates at a density of 500 cells/dish

135 and incubated for 8-12 days. The cells were washed with PBS, stained with Giemsa solution, and

136 colored with hematoxylin. Colonies with more than 50 cells were counted. At least 3 independent

137 experiments were carried out under identical conditions.

\section{$\begin{array}{lll}138 & 2.7 & \text { Cell migration and invasion analysis }\end{array}$}

139 Cell migration and invasion assays were carried out in 24-well Transwell chambers containing inserts

140 with a pore size of $8 \mu \mathrm{m}$ (Costar, Washington. DC, USA). For invasion assays, the inserts were

141 treated with $100 \mu \mathrm{L}$ Matrigel (1:9 dilution; BD Biosciences). 5x105 cells were seeded in the inserts,

142 and the cells on the upper membrane surface of the inserts were removed to the bottom membrane

143 surface after $24 \mathrm{~h}$. Cells were fixed with polyformaldehyde and stained with hematoxylin, and then

144 washed with PBS.

\section{$145 \quad 2.8 \quad$ Statistical analysis}

146 SPSS 17.0 software (SPSS lnc., Chicago, IL,USA) was used for statistical analysis. A Kaplan-Meier

147 estimator was used to analyze the prognosis of patients (25-26). Correlation between MEX3A

148 expression and clinicopathological features were examined by chi-squared tests, and the differences

149 between cell groups were compared by paired t-tests. Two-tailed P-values $<0.05$ were considered

150 statistically significant.

\section{$151 \quad 3 \quad$ Results}

\section{3.1 Patient demographics and clinicopathological characteristics}


Of the 87 patients enrolled in our study, 63 were men and 24 were women, all between the ages of 37 and 77. According to the seventh edition of the International Union against Cancer (UICC) Tumor,

Node, Metastasis (TNM) Staging System for Lung Cancer, patients were categorized as having stage I ( $n=29)$, II ( $n=19)$, or III ( $n=39)$ lung cancer. The histological diagnoses and differentiation grades of the tissue samples were evaluated according to the World Health Organization (WHO) classification system as either adenocarcinoma $(n=40)$ or squamous cell carcinoma $(n=47)$. Cancer cells were highly differentiated in 31 patients and moderately or poorly differentiated in the remaining 56. Lymph node metastases were present in 45 patients. In 40 patients, the tumor was smaller than $3 \mathrm{~cm}$.

\subsection{MEX3A is highly expressed in NSCLC and correlated with poor prognosis}

Analysis of MEX3A protein expression by immunocytochemistry of tumor samples from 87 patients with NSCLC indicated that the expression of MEX3A in tumor tissues was significantly higher than in the interstitium, bronchus, and alveoli. We also found that MEX3A was located in nuclei (Figure 1A). Western blots detected the expression of MEX3A in tumor tissues and paracancerous tissues, the results were consistent with those of immunocytochemistry (Figure 1B). Analysis of MEX3A protein expression levels as they relate to clinical parameters, we found that MEX3A levels correlated with differentiation $(\mathrm{P}=0.044)$, tumor size $(\mathrm{P}=0.020)$, lymph node metastasis $(\mathrm{P}=0.001)$, and $\mathrm{p}$-TNM stage $(\mathrm{P}=0.009)$, but did not vary significantly with age $(\mathrm{P}=0.295)$, gender $(\mathrm{P}=0.473)$, or tumor histological type $(\mathrm{P}=0.838)$ (Table 2$)$. Kaplan-Meier analysis demonstrated that MEX3A is statistically significant in the poor prognosis of NSCLC (Figure 1D).

172 Furthermore, western blotting of MEX3A protein expression in NSCLC cell lines and normal 173 bronchial epithelial HBE cells was conducted (Figure 1C). H661, and H292 showed the highest 174 MEX3A expression levels; H460 showed the lowest expression level; and A549 and H1299 were in 
175 the middle. Therefore, A549 and H1299 cells were used for subsequent experiments to explore the 176 impact of MEX3A in NSCLC.

177

\subsection{MEX3A promotes the proliferation of NSCLC.}

In order to investigate whether MEX3A regulates the proliferation of NSCLC, we transfected A549 and H1299 cells with either MEX3A-siRNA to knockdown MEX3A expression or MEX3A-plasmids to increase its expression. When MEX3A expression decreased by $50 \%$ or increased by $100 \%$, transfection was considered to have been effective. The colony forming ability of A549 cancer cells was inhibited in cells treated with MEX3A-siRNA $(\mathrm{P}=0.0002)$ and enhanced in those transfected with MEX3A-plasmids when compared to control $(\mathrm{P}=0.0007)$. Similar results were obtained in the H1299 cell line $(\mathrm{P}=0.0004$ and $\mathrm{P}=0.0008$, respectively) (Figure 2A). Next, the results of an MTT assay demonstrated that the proliferation ability of cells treated with MEX3A-siRNA was reduced, whereas this ability was strengthened in cells treated with MEX3A-plasmids in both A549 and H1299 cells when compared with control (A549: $\mathrm{P}=0.0056$ and $\mathrm{P}=0.0011 ; \mathrm{H} 1299$ : $\mathrm{P}=0.0002$ and $\mathrm{P}$ 0.0003 ) (Figure 2B).

Finally, in western blots of A549 cells treated with MEX3A-siRNA or MEX3A-plasmids, we found that compared with control cells, the expression of Cyclina2 ( $\mathrm{P}=0.0082$ and $\mathrm{P}=0.048$, respectively), CDK4 $(\mathrm{P}=0.0151$ and $\mathrm{P}=0.0092$, respectively $)$, and $\mathrm{CDK} 6(\mathrm{P}=0.0024$ and $\mathrm{P}=0.0001$, respectively) was decreased in MEX3A-siRNA treated cells, and increased in cells transfected with MEX3Aplasmids (Figure 2C). Similar results were obtained in H1299 cells (Cyclina2: $\mathrm{P}=0.0052$ and $\mathrm{P}=0.0002 ; \mathrm{CDK} 4: \mathrm{P}=0.0462$ and $\mathrm{P}=0.0002 ; \mathrm{CDK} 6: \mathrm{P}=0.0157$ and $\mathrm{P}=0.0027$; all values reflect MEX3A-siRNA and -plasmid, respectively) (Figure 2D). These results indicate that MEX3A can promote the proliferation of NSCLC.

\subsection{MEX3A promotes the migration and invasion of NSCLC}


In order to investigate whether MEX3A can regulate the migration and invasion of NSCLC, we once again transfected A548 and H1299 cells with either MEX3A-siRNA or MEX3A-plasmids. In Transwell assays without Matrigel, cells treated with MEX3A-siRNA demonstrated a weaker migration ability (A549: $\mathrm{P}=0.0047$; H1299: $\mathrm{P}=0.0032$ ), and cells transfected with MEX3A-plasmids demonstrated a stronger migration ability (A549: $\mathrm{P}=0.0006 ; \mathrm{H} 1299: \mathrm{P}=0.0003)$. Similar results were obtained for both cell lines in Transwell assays with Matrigel, suggesting that MEX3A promotes the invasion ability of cancer cells (A549: $\mathrm{P}=0.00403$ and $\mathrm{P}=0.0002 ; \mathrm{H} 1299$ : $\mathrm{P}=0.0029$ and $\mathrm{P}=0.0005$; values reflect MEX3A-siRNA and -plasmid, respectively) (Figure 3A).

Finally, western blots of A549 cells transfected with MEX3A-siRNA and MEX3A-plasmids demonstrated decreased expression of RhoA and matrix metalloproteinase 2 (MMP2) in MEX3AsiRNA treated cells (RhoA: $\mathrm{P}=0.0146 ; \mathrm{MMP} 2: \mathrm{P}=0.0147)$, and increased expression in cells transfected with MEX3A-plasmids when compared with control (RhoA: $\mathrm{P}=0.0453$; MMP2: $\mathrm{P}=0.0273$ ) (Figure 3B). Similar results were obtained for H1299 cells (Figure 3C) (RhoA: $\mathrm{P}=0.0003$ and $\mathrm{P}=0.0007 ; \mathrm{MMP} 2 \mathrm{P}=0.0012$ and $\mathrm{P}=0.0004)$. These results indicate that MEX3A promotes the migration and invasion of NSCLC.

\subsection{MEX3A activates the MEK/ERK pathway}

In order to explore how MEX3A regulate NCSLS, we used western blots of A549 cells to determine the expression levels of proteins in signal transduction pathways. Compared with control cells, the expression of phosphorylated-ERK (P-ERK) and phosphorylated-MEK (P-MEK) decreased in MEX3A-siRNA treated cells (P-ERK: $\mathrm{P}=0.0009$; P-MEK: $\mathrm{P}=0.0028$ ), whereas expression of $\mathrm{P}-\mathrm{ERK}$ and P-MEK increased in cells transfected with MEX3A-plasmids (P-ERK: $\mathrm{P}=0.0005$; P-MEK: $\mathrm{P}=0.0002$ ). The expression of ERK was unaffected in both treatments when compared to control (Figure 4A). Similar results were achieved in H1299 cells (Figure 4B) (P-ERK: P=0.0226 and 
$\mathrm{P}=0.0002$; $\mathrm{P}-\mathrm{MEK}: \mathrm{P}=0.0053$ and $\mathrm{P}=0.0007$; values reflect MEX3A-siRNA and -plasmid,

222 respectively).

$223 \quad 3.6$ MEX3A promotes the biological behavior of NSCLC by activating the MEK/ERK pathway

To investigate whether MEX3A can promote the biological behavior of NSCLC through the

MEK/ERK signaling pathway, MEX3A-plasmid transfected A549 and H1299 cells were treated with

DMSO or U0126 (an ERK pathway inhibitor). The colony forming ability of MEX3A-plasmid

transfected cells was inhibited when treated with U0126 (A549: $\mathrm{P}=0.0007$ and $\mathrm{P}=0.0009$; H1299:

$\mathrm{P}=0.0002$ and $\mathrm{P}=0.0002$; for each group values are control vs. transfection and transfection vs.

transfection + U0126, respectively) (Figure 5A). Similar results were observed in MTT assays and

Transwell assays both with and without Matrigel ( Table 3) (Figure 5B and C). These results suggest

that U0126 inhibited the proliferation, migration, and invasion of cancer cells, which further suggests

that MEX3A promotes the proliferation, migration, and invasion of NCSLS by activating the

MEK/ERK pathway.

\section{5}

\section{Discussion}

In the present study, we have demonstrated that MEX3A can promote the progression of NSCLC. MEX3A was mainly localized to the nucleus of all tissues, and its expression was enhanced in NSCLC tissues. Moreover, MEX3A expression was positively correlated with the differentiation of NSCLC, the size of cancer nests, whether there was lymph node metastasis or not, and pTNM. In our study, we demonstrated that MEX3A can promote the proliferation, migration, and invasion of NSCLC cells. To explore the mechanism by which MEX3A promotes the biological behavior of NSCLC, we determined the expression of cyclin related proteins, cyclin-binding proteins, and migration and invasion related proteins. Finally, we screened for protein expression associated with 
several tumor related pathways such as $\mathrm{AKT}, \mathrm{NF}-\kappa \mathrm{B}, \mathrm{NOTCH}$, and $\mathrm{mTOR}$, and found that the expression of proteins in the MAPK pathway were influenced by MEX3A levels. However, the relationship between MEX3A and MAPK had not been previously explored.

MAPK is an evolutionarily conserved signal regulator, which regulates many cellular functions. There are four members of the MAPK family, ERK1/2, JNK, p38, and ERK5. ERK1/2 is the primary contributor to the MAPK signaling pathway, which is the most important signal transduction pathway between cell membrane receptors and the intracellular environment. MAPK signaling plays an important role in the development of a variety of malignant tumors (29). Our research focused on the regulatory effects of MEX3A on ERK1/2. ERK1/2 is phosphorylated following the activation of RAS, RAF, and MEK (30,31). Once phosphorylated, ERK1/2 is activated and transmits extracellular signals, causing a series of effects, including cell proliferation, apoptosis, differentiation, invasion, and metastasis, thus promoting the occurrence and development of tumors (32). It has been shown that in gastric cancer cells, knockdown of MEX3A with siRNA can inhibit the proliferation and migration of cancer cells, but the mechanism by which this occurs unclear (14). MEX3A has also been shown to have a negative regulatory effect on CDX2, a homeobox transcription factor, in Caco-2 and AGS cells (13). MEX3A inhibits the expression of CDX2 in the gastrointestinal environment, which affects intestinal differentiation, polarity, and stem cell characteristics, which are key mechanisms of tissue homeostasis (13). MEX3A interacts with the MEX-3 recognition element (MRE) located in the 3'-untranslated region of CDX2 mRNA (13). We can predict whether MEX3A can interact with the mRNA of proteins in the MAPK pathway by screening for the sequence of this MEX-3 recognition element. Previous studies have shown that MEX3A is a component of $\mathrm{P}$ bodies and interacts with hDcpla, a decapping factor (27). $\mathrm{P}$ bodies are the sites of RNA decay and storage of untranslated transcript (27). Therefore, MEX3A may be regulate the mRNA of MAPK pathway genes by forming $\mathrm{P}$ bodies, thus affecting the development of 

components of silencing RNA in, which are closely related to tumor development. Therefore, through its interaction with Ago proteins, MEX3A may affect the transcription of MAPK pathway related proteins. Previous studies on colorectal cancer have shown that high expression of MEX3A

272 confers resistance to chemotherapy and $\gamma$-rays (12). Currently, drug resistance is a significant

273 obstacle during the course of chemotherapy as treatment for NSCLC. This study suggests that

274 MEX3A is a potential target for the relief of drug resistance.

In future studies, we will focus on the effect of MEX3A on the transcription of related genes. We will detect the RNA content of various genes to determine the regulatory effect of MEX3A on transcription. The histochemical results of our study suggested that MEX3A was predominately expressed in the nucleus. However, previous studies have shown that MEX3A is present in both the nucleus and the cytoplasm and can shuttle between them. We will observe the localization of MEX3A in cells in response to various treatments of cells such as transfection or U0126. This will allow us to elucidate the mechanisms behind the shuttling of MEX3A between the nucleus and cytoplasm. It is also critical to determine the mechanism by which MEX3A promotes the biological behavior of NSCLC beyond its influence on the MEK/ERK pathway. In addition, by simulating radiotherapy and chemotherapy on NSCLC cells, we can elucidate how the expression of MEX3A effects treatment resistance in NSCLC. Drug resistance is a major obstacle in tumor treatment and if we can contribute relieving this issue, we will vastly improve tumor treatment.

\section{Conclusion}

In summary, our study has shown that MEX3A is related to the poor prognosis of NSCLC by promoting the expression of cell proliferation proteins, and those involved in migration and invasion of cancer cells. Moreover, the expression of proteins within the MAPK pathway were enhanced by 
291 MEX3A. These results indicate that MEX3A has potential as a target for future clinical treatments of

292 NSCLC.

\section{List of abbreviations}

294 MEX3A: MEX3 homolog A; Ago: Argonaute; CDX2: Caudal type homeobox 2; NSCLC: Non295 small-cell lung carcinoma; ERK: Extracellular regulated protein kinases; P-body: Processing body;

296 MEM: Modified Eagle medium; PBS: Phosphate-buffered saline; MMP: Matrix metalloproteinase;

297 siRNA: Small-interfering RNA; MAPK: Mitogen-activated protein kinase. TNM: Tumor, Node, 298 Metastasis; UICC: International Union against Cancer; WHO: World Health Organization; MRE:

299 MEX-3 recognition element.

3007 Declarations

301 Ethics approval and consent to participate: This study was approved by the Medical Research Ethics

302 Committee of China Medical University and informed consent was obtained from all patients.

303 Consent for publication: not applicable

304 Availability of data and materials:

Datasets generated and/or analysed during the current study are available in the UNIPROT repository, 306 https://www.uniprot.org/

307 Competing interest: The authors declare that they have no competing interests.

308 Funding: This work was supported by the Liaoning Province Colleges and Universities Innovation 309 Team (LN2015029), Lianing Provincial Education Department. 
310 Authors' contributions: ZY designed the study, conducted experiments, acquired and analyzed data,

311 and wrote the manuscript. ZB, HJ, YT, JJ, WD, QF, QZ, HB, XZ, ZF and ZA conducted the

312 experiments and acquired data. XQ was responsible for the conception and supervision of the study

313 and wrote the manuscript. All authors corrected drafts and approved the final version of the

314 manuscript.

315 Acknowledgements: We thank Editage (www.editage.cn) for English language editing.

3168 References

317 1. Jemal A, Siegel R, Xu J, Ward E. Cancer statistics, 2010. CA Cancer J Clin 2010;60:277-300.

318 2. Siegel RL, Miller KD, Jemal A. Cancer statistics, 2016. CA Cancer J Clin 2016;66:7-30.

319 3. Torre LA, Bray F, Siegel RL, Ferlay J, Lortet-Tieulent J, Jemal A. Global cancer statistics, 2012.

$320 \quad$ CA Cancer J Clin 2015;65:87-108.

321 4. Travis WD. Pathology of lung cancer. Clin Chest Med 2002;23:65-81, viii.

322 5. Jemal A, Siegel R, Ward E, Hao Y, Xu J, Thun MJ. Cancer statistics, 2009. CA Cancer J Clin $323 \quad 2009 ; 59: 225-249$.

324 6. Minna JD, Roth JA, Gazdar AF. Focus on lung cancer. Cancer Cell 2002;1:49-52.

325 7. Buchet-Poyau K, Courchet J, Le Hir H, Séraphin B, Scoazec J-Y, Duret L, et al. Identification and 326 characterization of human Mex-3 proteins, a novel family of evolutionarily conserved RNA-binding 327 proteins differentially localized to processing bodies. Nucleic Acids Res 2007;35:1289-1300.

328 8. Ciosk R, DePalma M, Priess JR. Translational regulators maintain totipotency in the 329 Caenorhabditis elegans germline. Science 2006;311:851-3. 
9. Fornerod M, Ohno M, Yoshida M, Mattaj IW. CRM1 is an export receptor for leucine-rich nuclear 331 export signals. Cell 1997;90:1051-60.

10. Parisi C, Giorgi C, Batassa EM, Braccini L, Maresca G, D'agnano I, et al. Ago1 and Ago2 differentially affect cell proliferation, motility and apoptosis when overexpressed in SH-SY5Y neuroblastoma cells. FEBS Lett 2011;585:2965-71.

11. Cano F, Bye H, Duncan LM, Buchet-Poyau K, Billaud M, Wills MR, et al. The RNA-binding E3 ubiquitin ligase MEX-3C links ubiquitination with MHC-I mRNA degradation. EMBO J 2012;31:3596-606.

12. Barriga FM, Montagni E, Mana M, Mendez-Lago M, Hernando-Momblona X, Sevillano M, et al. 339 Mex3a Marks a Slowly Dividing Subpopulation of Lgr5+ Intestinal Stem Cells. Cell Stem Cell $340 \quad 2017 ; 20: 801-16 . e 7$.

13. Pereira B, Sousa S, Barros R, Carreto L, Oliveira P, Oliveira C, et al. CDX2 regulation by the RNA-binding protein MEX3A: impact on intestinal differentiation and stemness. Nucleic Acids Res 2013;41:3986-99.

14. Jiang H, Zhang X, Luo J, Dong C, Xue J, Wei W, et al. Knockdown of hMex-3A by small RNA interference suppresses cell proliferation and migration in human gastric cancer cells. Mol Med Rep 2012;6:575-80. metastasis. Curr Opin Cell Biol 2012;24:277-83. motility. Cell Adh Migr 2011;5:170-80. 
353 18. Gong L, Wu D, Zou J, Chen J, Chen L, Chen Y, et al. Prognostic impact of serum and tissue

354 MMP-9 in non-small cell lung cancer: a systematic review and meta-analysis. Oncotarget

$355 \quad 2016 ; 7: 18458-68$

19. Vandooren J, Van den Steen PE, Opdenakker G. Biochemistry and molecular biology of gelatinase B or matrix metalloproteinase-9 (MMP-9): the next decade. Crit Rev Biochem Mol Biol $2013 ; 48: 222-72$. cycle and breast cancer. Endocr Relat Cancer 2004;11:603-22.

22. Hall M, Peters G. Genetic alterations of cyclins, cyclin-dependent kinases, and Cdk inhibitors in human cancer. Adv Cancer Res 1996;68:67-108.

23. Sherr CJ. D-type cyclins. Trends Biochem Sci 1995;20:187-90.

24. Graña X, Reddy EP. Cell cycle control in mammalian cells: role of cyclins, cyclin dependent kinases (CDKs), growth suppressor genes and cyclin-dependent kinase inhibitors (CKIs). Oncogene 1995;11:211-9.

25. Lánczky A, Nagy Á, Bottai G, Munkácsy G, Szabó A, Santarpia L, et al. miRpower: a web-tool to validate survival-associated miRNAs utilizing expression data from 2178 breast cancer patients. Breast Cancer Res Treat 2016;160:439-46. 
372 prognostic value of biomarkers using transcriptomic data in non-small-cell lung cancer. PLoS ONE $373 \quad 2013 ; 8: \mathrm{e} 82241$.

374 27. Almeida R, Silva E, Santos-Silva F, Silberg DG, Wang J, De Bolós C, et al. Expression of 375 intestine-specific transcription factors, CDX1 and CDX2, in intestinal metaplasia and gastric 376 carcinomas. J Pathol 2003;199:36-40.

377 28. Silberg DG, Sullivan J, Kang E, Swain GP, Moffett J, Sund NJ, et al. Cdx2 ectopic expression 378 induces gastric intestinal metaplasia in transgenic mice. Gastroenterology 2002;122:689-96.

379 29. Kohno M, Pouyssegur J. Targeting the ERK signaling pathway in cancer therapy. Front $380 \quad$ Endocrinol 2017; 312

381 Palanisamy N, Ateeq B, Kalyana-Sundaram S. Rearrangements of the RAF kinase pathway in 382 prostate cancer, gastric cancer and melanoma. Nat Med 2010;16(7);200-211

30. Akasaka E, Takekoshi S, Horikoshi Y. Protein oxidative damage and heme oxygenase in 384 sunlight-exposed human skin: roles of MAPK responses to oxidative stress. Tokai J Exp Clin Med $385 \quad 2010 ; 35(4) ; 152-164$

386 31. Nucera C, Lawler J, Parangi S. BRAF(V600E) and microenvironment in thyroid cancer: a 387 functional link to drive cancer progression. Cancer Res 2011;71(7); 2417-2422

Figure 1 

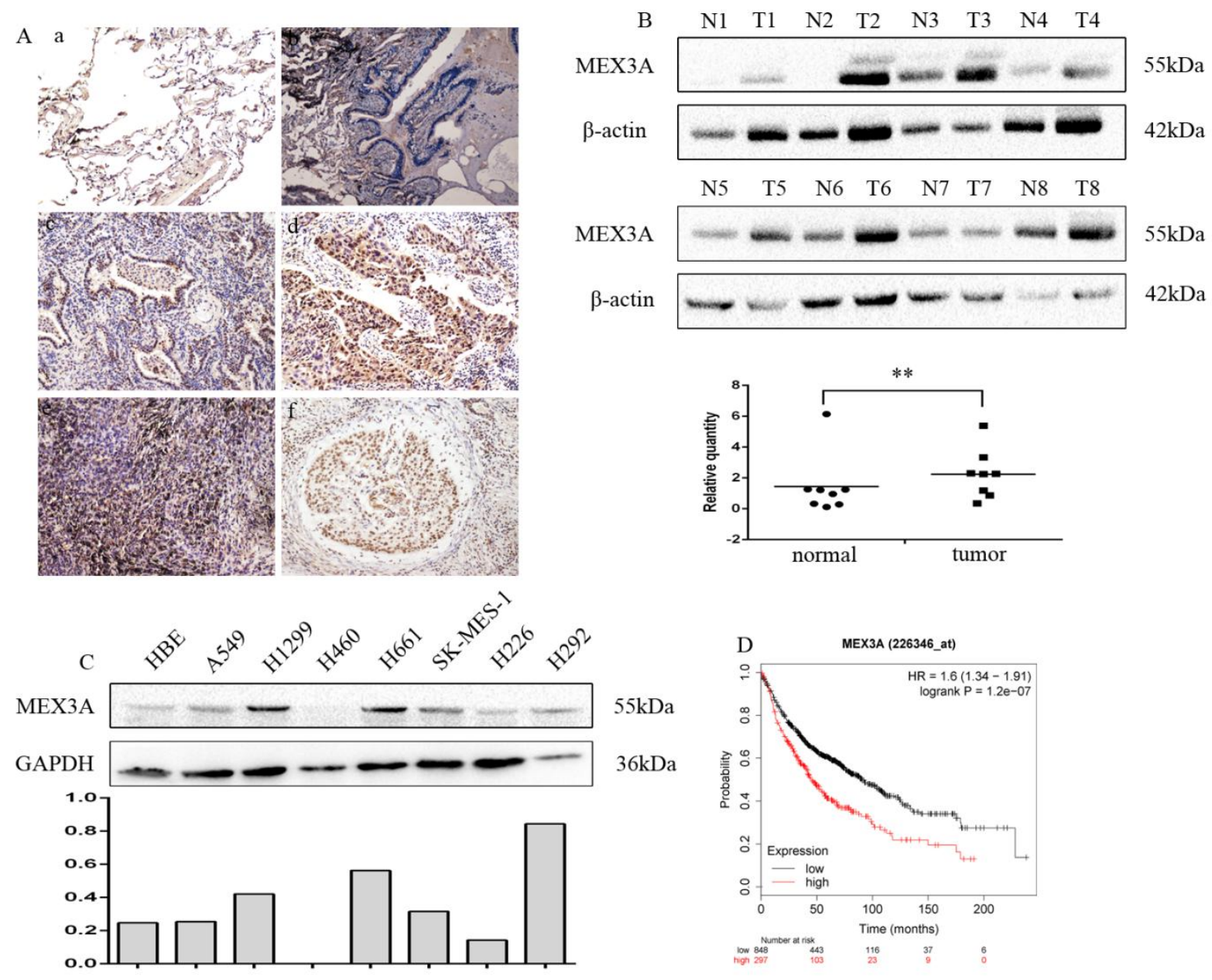

Expression of MEX3A in non-small cell lung cancer (NSCLC) tissues and cell lines. A. protein expression as analyzed by immunohistochemistry in (a) alveolar and (b) normal bronchial epithelial cells; (c) well-differentiated adenocarcinoma and (d) poorly-differentiated adenocarcinoma; (e) well-

394 differentiated squamous cell carcinoma and (f) poorly-differentiated squamous cell carcinoma.

395 Magnification: $\times 200$. B. Relative expression of MEX3A protein in eight paired NSCLC samples and 396 adjacent normal lung tissue. C. MEX3A protein levels in seven lung cancer cell lines and a normal bronchial cell line (HBE) were assessed by immunoblotting and analyzed with ImageJ software. D.

398 Survival of NSCLC patients with respect to MEX3A expression was analyzed with a Kaplan-Meier 399 curve; hazard ratio (HR) and P-value are indicated. 
Figure 2
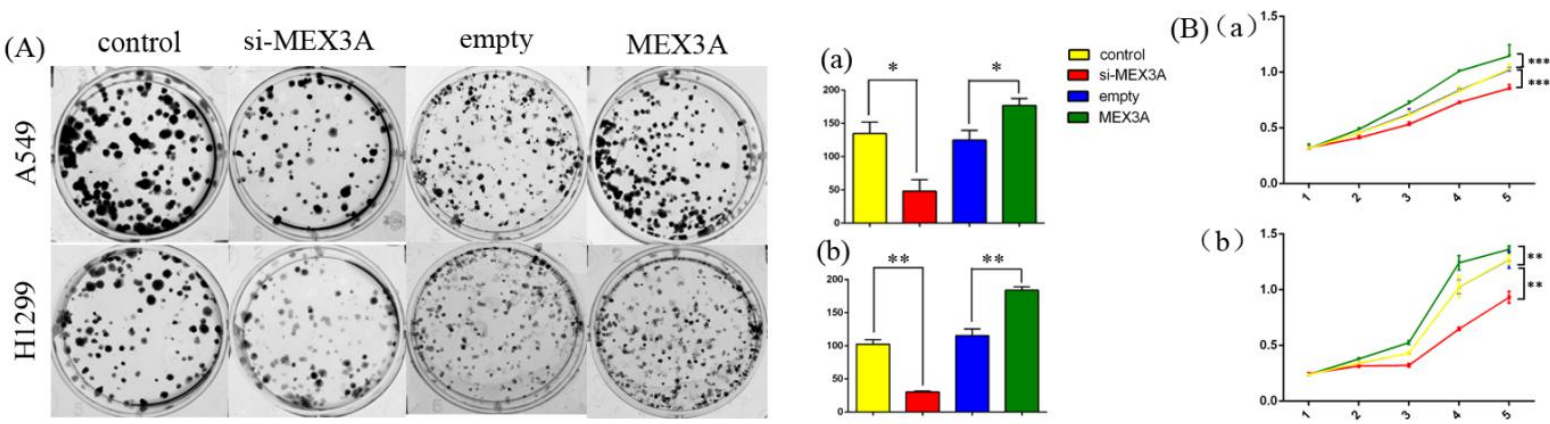

(b)
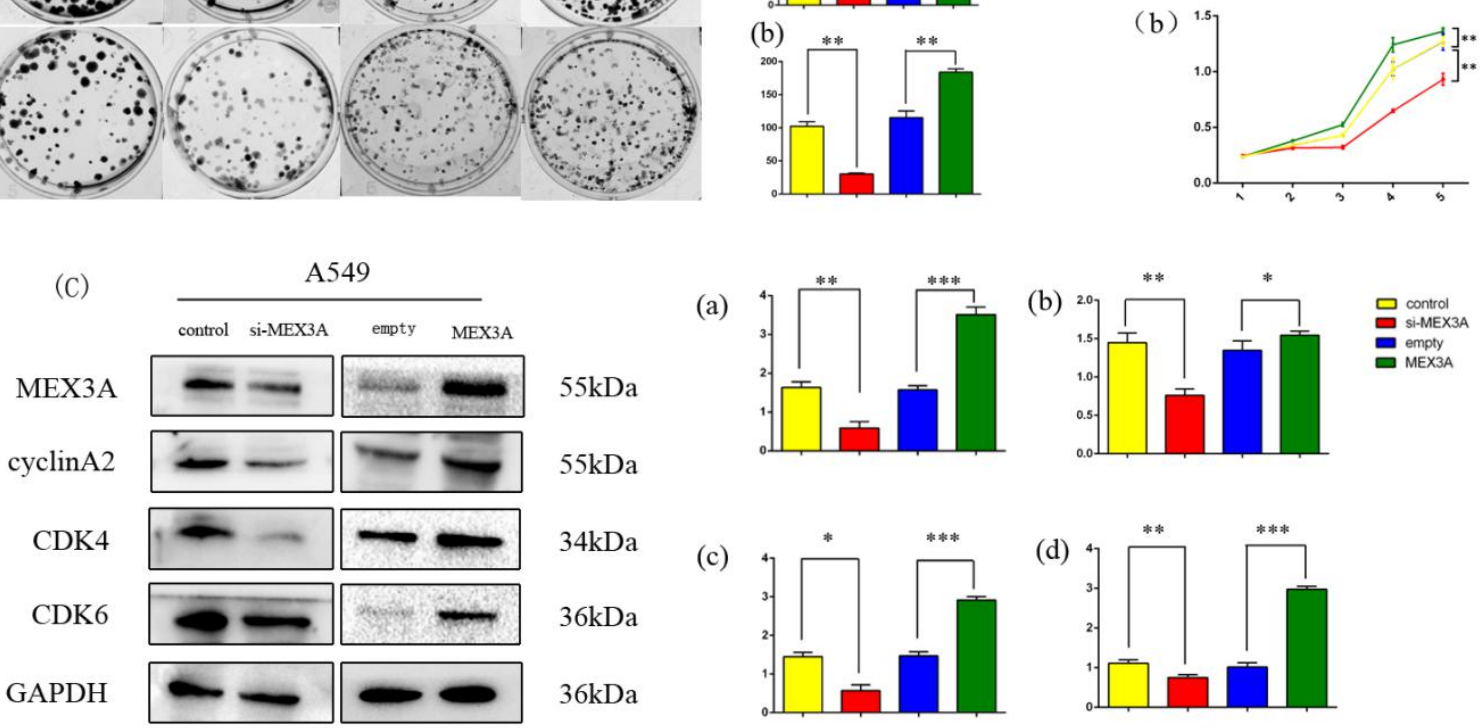

(a)

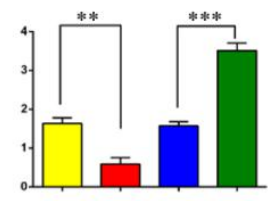

(b)

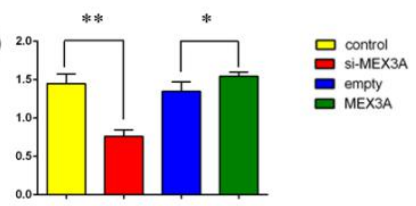

(D)

H1299

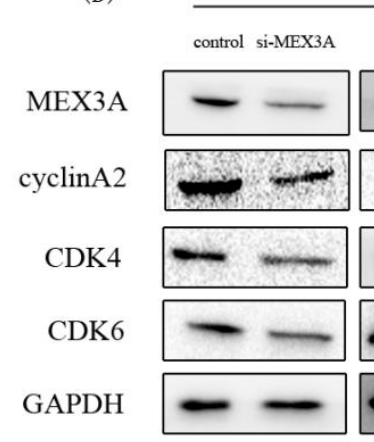

empty MEX3A

$55 \mathrm{kDa}$

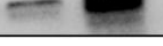

$55 \mathrm{kDa}$

(c)

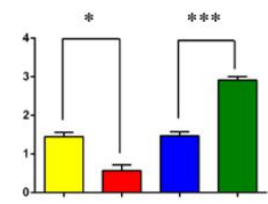

(a)

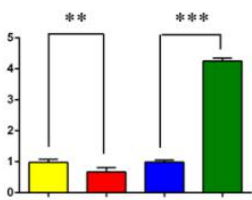

(c)

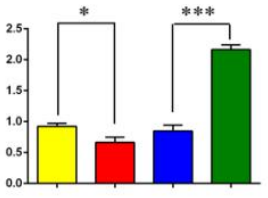

(d)

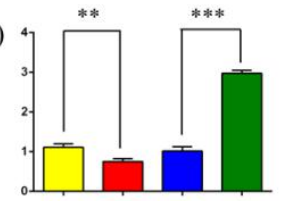

(b)

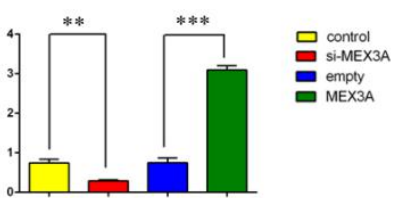

(d)

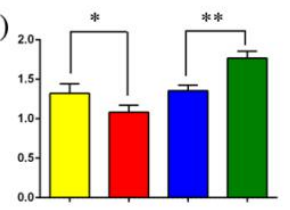

402

403

Effect of MEX3A expression on colony formation and proliferation of NSCLC cells. A549 and H1299 cells were transfected with MEX3A-specific siRNA (si-MEX3A) or control siRNA (control), or with a MEX3A expression plasmid (MEX3A) or vehicle (empty). ${ }^{*} \mathrm{P}<0.05,{ }^{*} \mathrm{P}<0.01$ and $* * * \mathrm{P}<0.001$. A. Colony formation assay. (a) A549: si-MEX3A vs control; MEX3A vs empty. (b) H1299: si-MEX3A vs control; MEX3A vs empty. B. MTT assay. (a) A549: si-MEX3A vs control; 
408

409

410

411

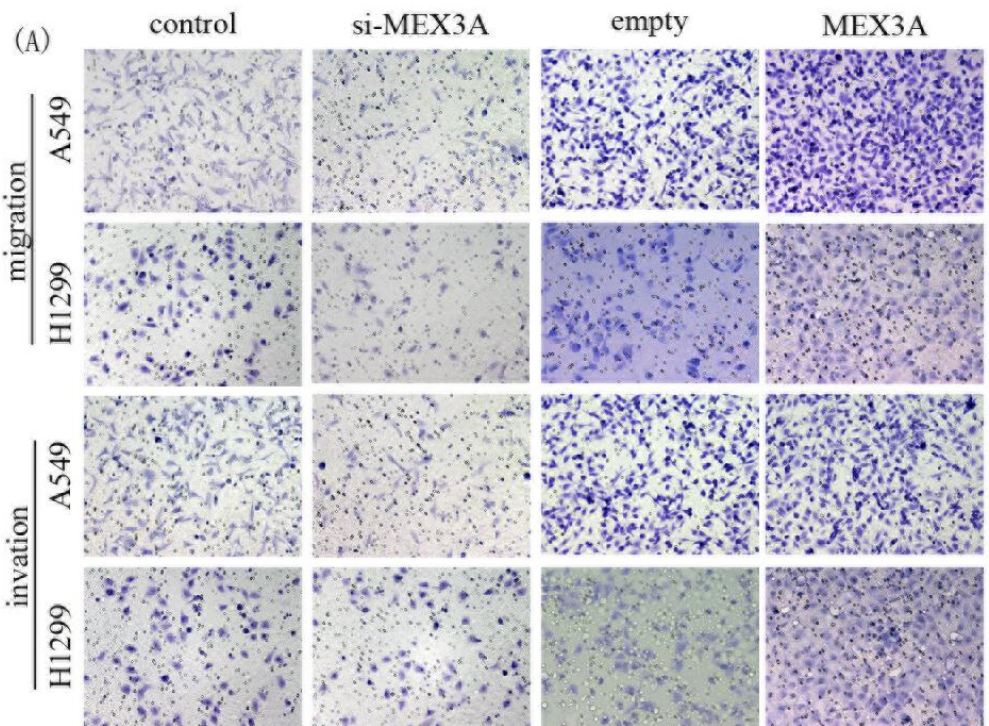

(a)

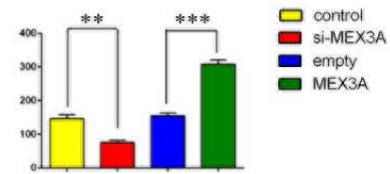

(b)

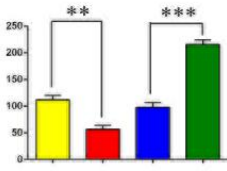

(c)

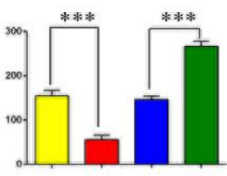

(d)

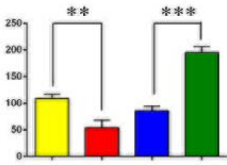

(B)
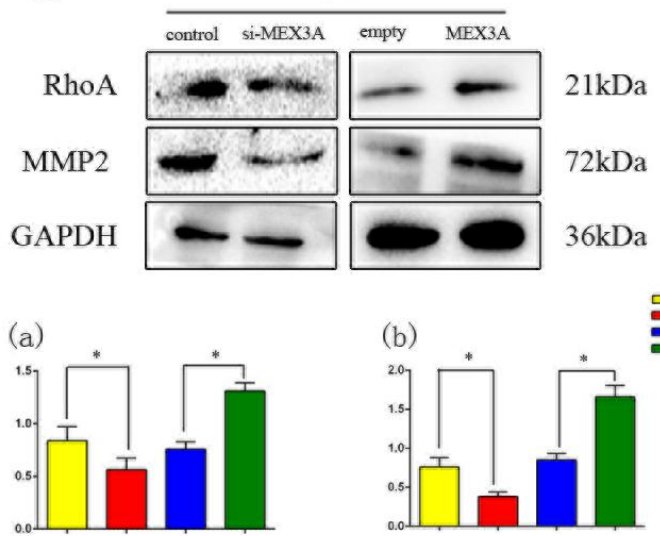

(C)
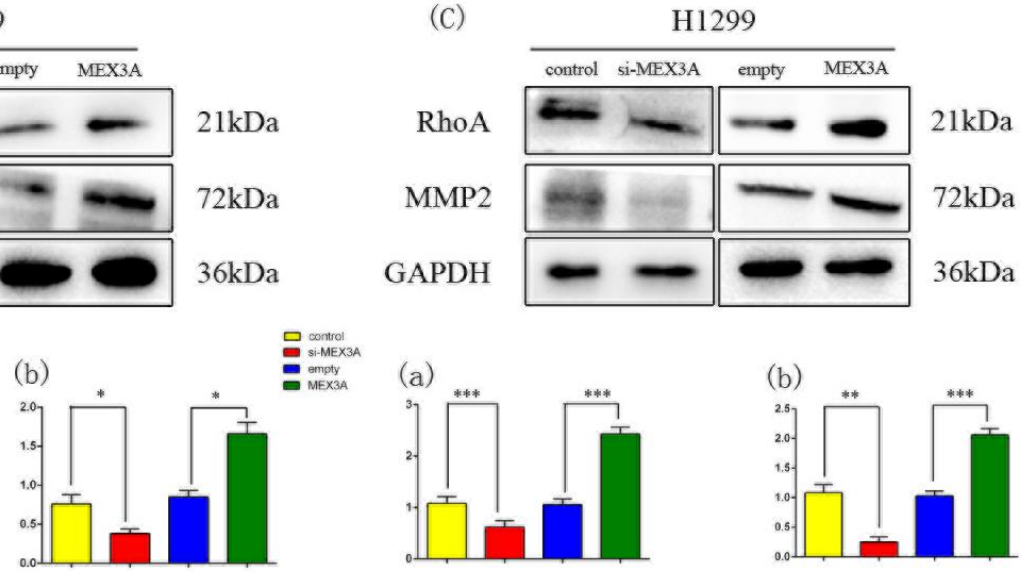
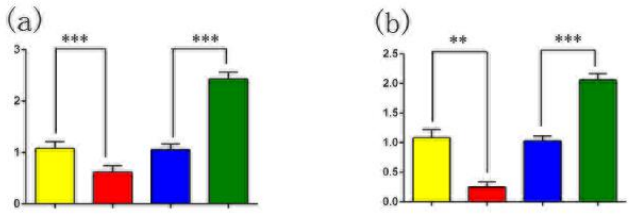

413 Effect of MEX3A expression on the migration and invasion of NSCLC cells. A549 and H1299 cells

414 were transfected with MEX3A-specific siRNA (si-MEX3A) or control siRNA (control), or with a

415 MEX3A expression plasmid (MEX3A) or vehicle (empty). $* \mathrm{P}<0.05, * * \mathrm{P}<0.01$ and $* * * \mathrm{P}<0.001$. A. 
416 Cell migration as analyzed by a Transwell migration assay; cells that migrated to the lower chamber 417 were stained with hematoxylin and counted. (a) A549 migration: si-MEX3A vs control; MEX3A vs 418 empty. (b) H1299 migration: si-MEX3A vs control; MEX3A vs empty. (c) A549 invasion: si-

419 MEX3A vs control; MEX3A vs empty. (d) H1299 invasion: si-MEX3A vs control; MEX3A vs 420 empty. B,C. Expression of MEX3A and cell migration- and invasion-related proteins in transfected 421 (B) A549 and (C) H1299 cells.
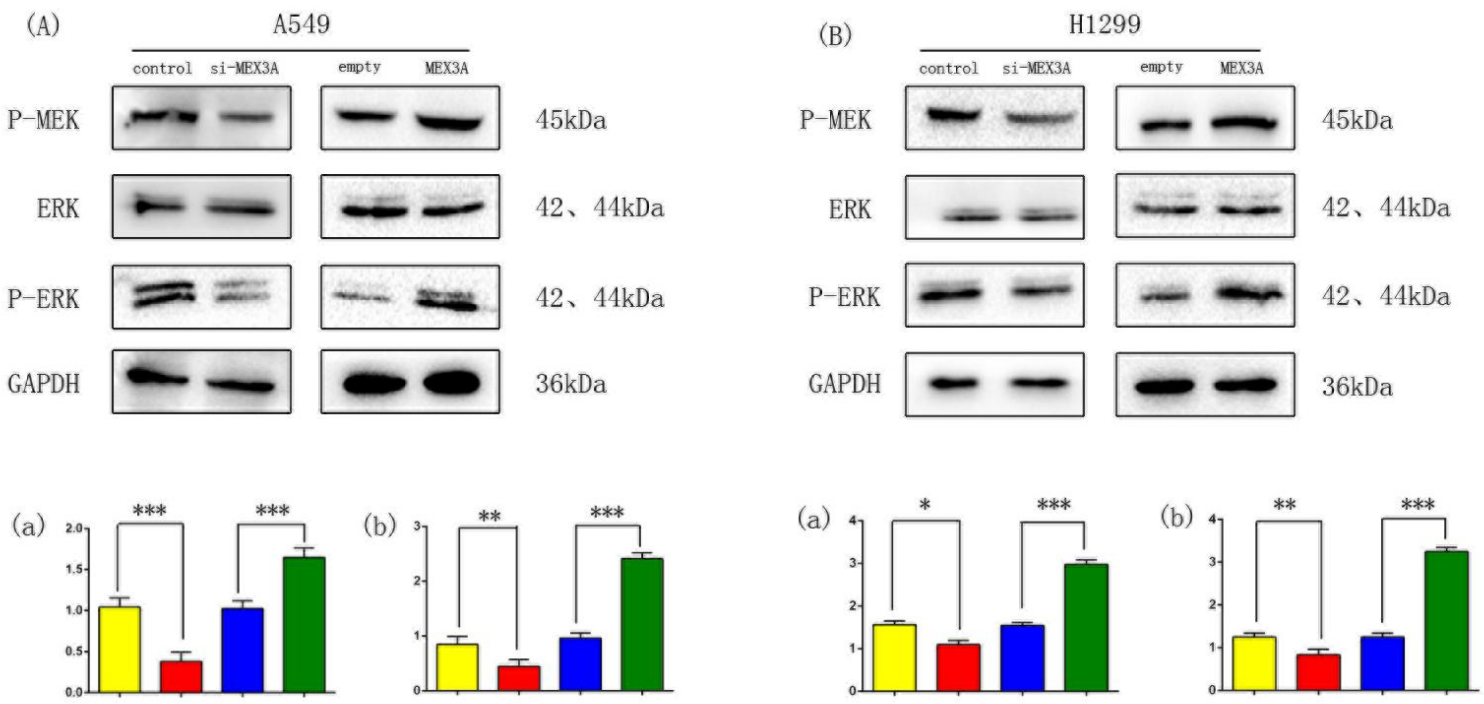

425 Changes in the expression of MAPK-related proteins in (A) A549 and (B) H1299. Relative 426 quantification analysis was based on grayscale values. $* \mathrm{P}<0.05, * * \mathrm{P}<0.01$ and $* * * \mathrm{P}<0.001$.

Figure 5 

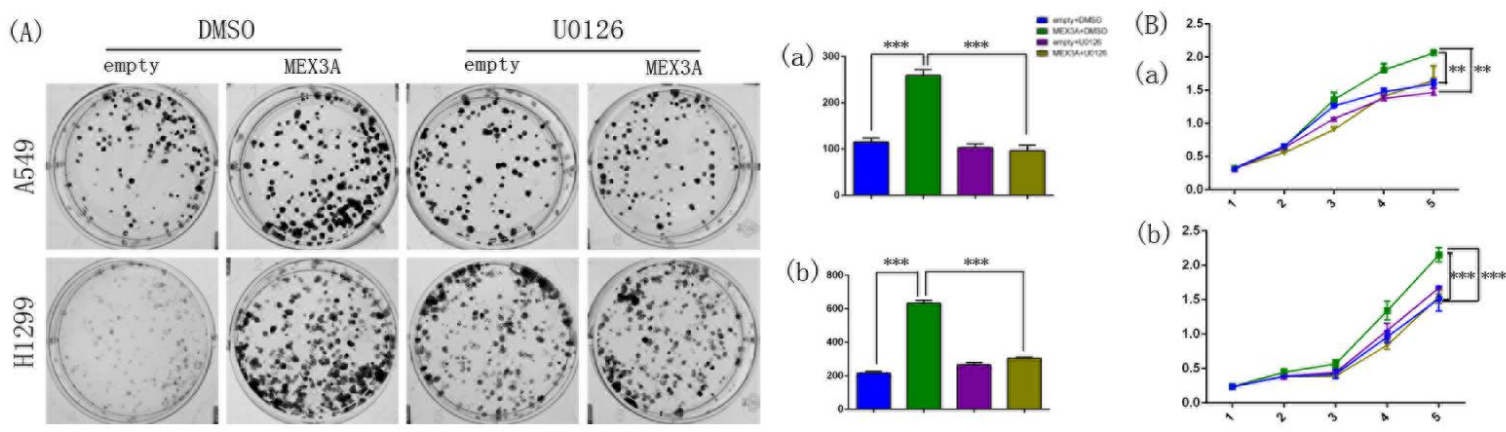

(C)
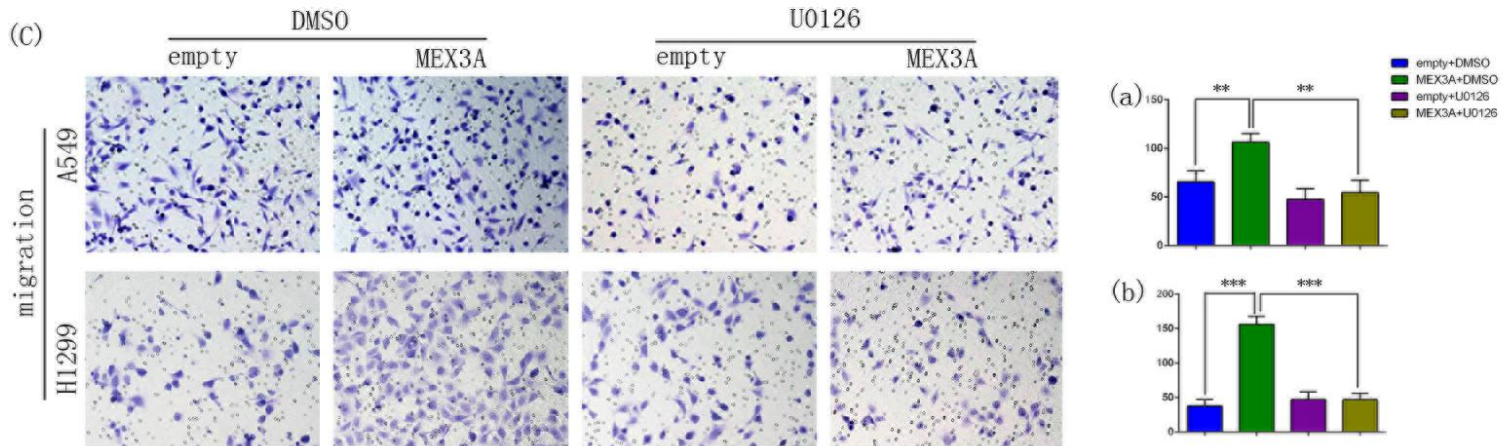

(b)
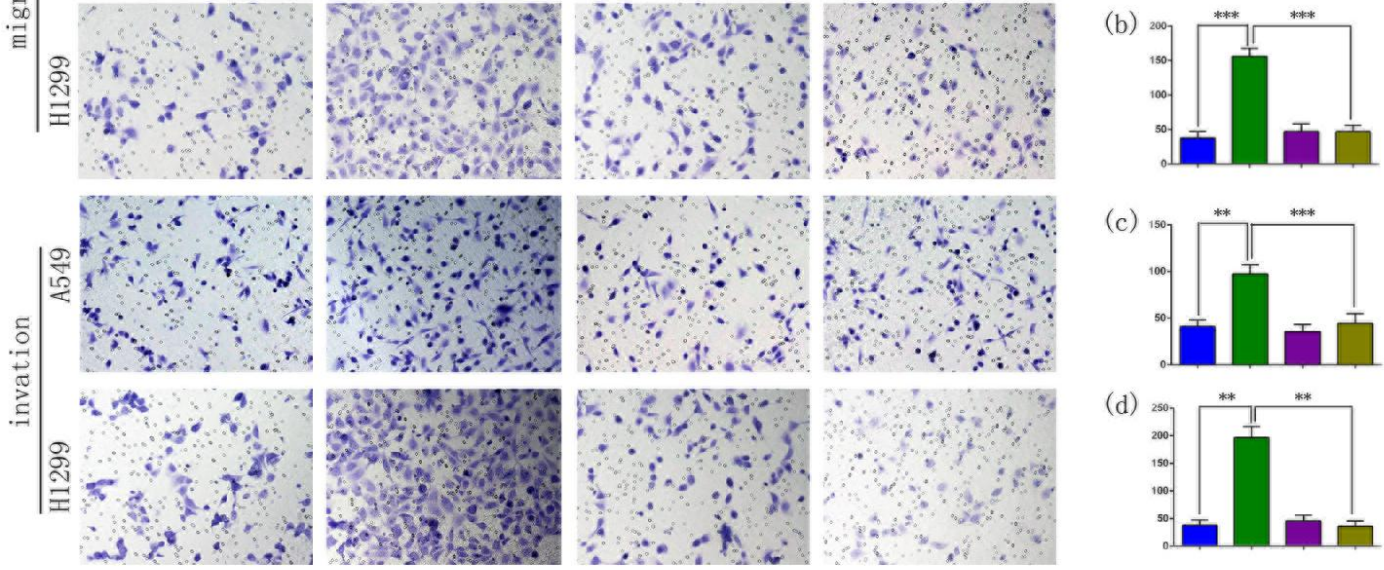

(c)

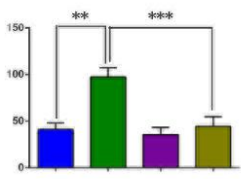

(d)

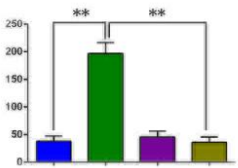

430 Effect of MEX3A with or without ERK inhibition on the behavior of NSCLC cells. A549 and H1299

431 cells transfected with a MEX3A expression plasmid were treated with the MEK inhibitor U0126 or

432 DMSO (control) and analyzed for cell proliferation: (A) colony formation assay and (B) MTT assay;

433 and (C) migration and invasion.

Table 1

Antibodies used for western blotting in the present study. 


\begin{tabular}{|c|c|c|c|c|}
\hline Antibody name & Source & Catalog number & Host & Dilution \\
\hline MEX3A & Sigma-Aldrich & PRS4869 & Rabbit & $1: 1000$ \\
\hline Actin & Proteintech & $600004-1-1 \mathrm{~g}$ & Mouse & $1: 10000$ \\
\hline GAPDH & Proteintech & $66009-1-\lg$ & Mouse & $1: 10000$ \\
\hline CyclinA2 & Cell Signaling Technology 1nc. & 465 & Mouse & $1: 1000$ \\
\hline CDK4 & Cell Signaling Technology lnc. & 1279 & Rabbit & $1: 1000$ \\
\hline CDK6 & Cell Signaling Technology lnc. & 1333 & Rabbit & $1: 1000$ \\
\hline RhoA & Cel1 Signaling Technology lnc. & 211 & Rabbit & $1: 1000$ \\
\hline MMP2 & Cell Signaling Technology 1nc. & 2099 & Rabbit & $1: 1000$ \\
\hline $\mathrm{P}-\mathrm{MEK}$ & Cel1 Signaling Technology lnc. & 912 & Rabbit & $1: 1000$ \\
\hline P-ERK & Cell Signaling Technology lnc. & 437 & Rabbit & $1: 1000$ \\
\hline ERK & Ce11 Signaling Technology lnc. & 469 & Mouse & $1: 1000$ \\
\hline
\end{tabular}

438 Table 2

439 Association of MEX3A expression with the clinical and pathological characteristics of NSCLC 440 patients.

Clinicopathological characteristics Total N MEX3A-negative MEX3A-positive P-value
\begin{tabular}{llllll|} 
Age (years) & 38 & 19 & & \\
\hline$\geqslant 60$ & 38 & 0.295 \\
\hline
\end{tabular}




\begin{tabular}{|c|c|c|c|c|}
\hline$<60$ & 49 & 19 & 32 & \\
\hline \multicolumn{5}{|l|}{ Gender } \\
\hline Male & 63 & 29 & 34 & 0.473 \\
\hline Female & 24 & 9 & 15 & \\
\hline \multicolumn{5}{|l|}{ Histological type } \\
\hline Squamous ccell carcinoma & 47 & 21 & 26 & 0.838 \\
\hline Adenocarcinoma & 40 & 17 & 23 & \\
\hline \multicolumn{5}{|l|}{ Differentiation } \\
\hline We11-Moderate & 31 & 18 & 13 & 0.044 \\
\hline Poor & 56 & 20 & 29 & \\
\hline \multicolumn{5}{|l|}{ Tumor size $(\mathrm{cm})$} \\
\hline$\geqslant 3$ & 47 & 15 & 32 & 0.02 \\
\hline$<3$ & 40 & 23 & 17 & \\
\hline \multicolumn{5}{|l|}{ Lymph node metastasis } \\
\hline Negative & 42 & 26 & 16 & 0.001 \\
\hline Positive & 45 & 12 & 33 & \\
\hline \multicolumn{5}{|l|}{ TNM stage } \\
\hline I & 48 & 27 & 21 & 0.009 \\
\hline II -III & 39 & 11 & 28 & \\
\hline
\end{tabular}


$442 \quad$ Table 3

$443 \quad \mathrm{P}$ value of result 3.6

\begin{tabular}{|l|lllr|}
\hline \multicolumn{2}{|c}{$\begin{array}{l}\text { colony information } \\
\text { assay }\end{array}$} & $\begin{array}{l}\text { MTT } \\
\text { assay }\end{array}$ & $\begin{array}{l}\text { Transwell without } \\
\text { Matrigel }\end{array}$ & Transwel1 with Matrigel \\
\hline A549 & 0.0047 & 0.0009 & 0.0076 & 0.0005 \\
\hline H1299 & 0.0004 & 0.0002 & 0.0006 & 0.0022 \\
\hline
\end{tabular}




\section{Figures}
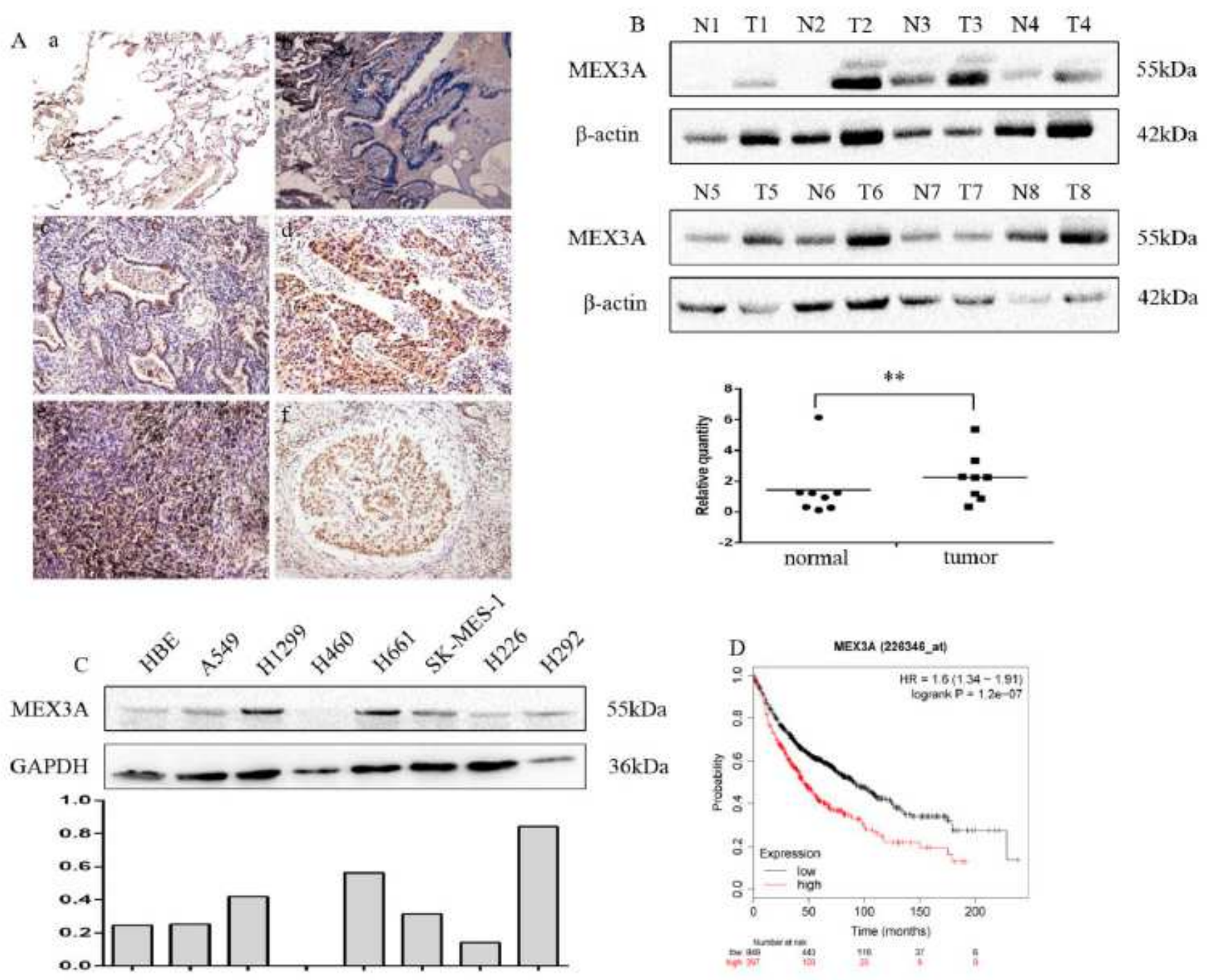

\section{Figure 2}

Expression of MEX3A in non-small cell lung cancer (NSCLC) tissues and cell lines. A. protein expression as analyzed by immunohistochemistry in (a) alveolar and (b) normal bronchial epithelial cells; (c) welldifferentiated adenocarcinoma and (d) poorly-differentiated adenocarcinoma; (e) well differentiated squamous cell carcinoma and (f) poorly-differentiated squamous cell carcinoma. Magnification: $\times 200$. $B$. Relative expression of MEX3A protein in eight paired NSCLC samples and adjacent normal lung tissue. C. MEX3A protein levels in seven lung cancer cell lines and a normal bronchial cell line (HBE) were assessed by immunoblotting and analyzed with ImageJ software. D. Survival of NSCLC patients with respect to MEX3A expression was analyzed with a Kaplan-Meier curve; hazard ratio (HR) and P-value are indicated. 


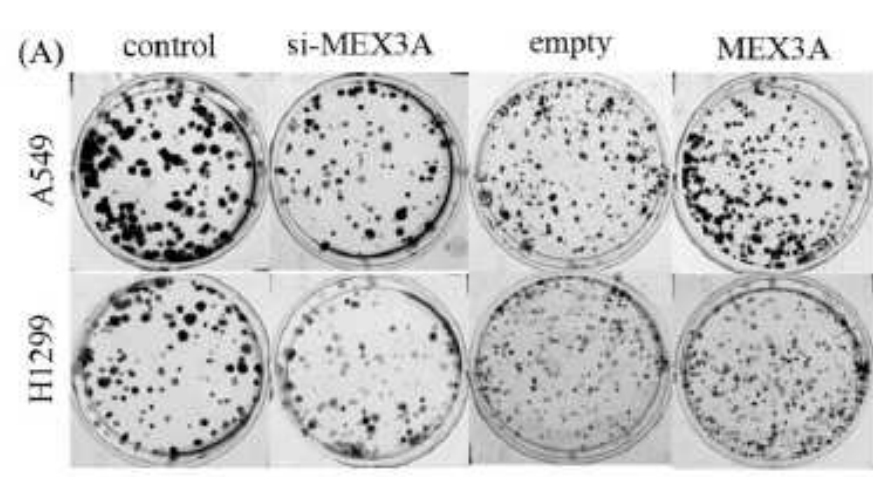

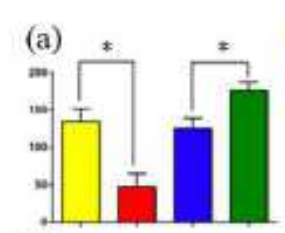

(b)

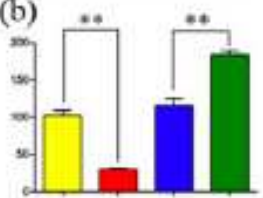

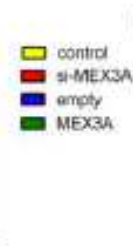

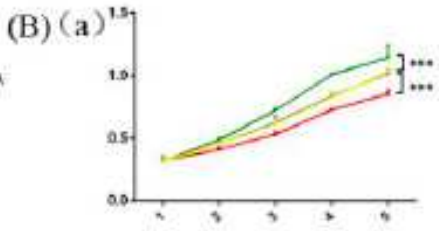

(b)

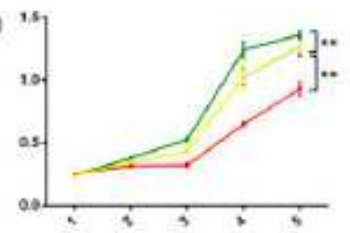

(a)

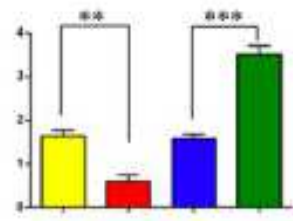

$55 \mathrm{kDa}$

34kDa

$36 \mathrm{kDa}$

CDK6

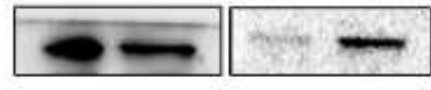

(c)
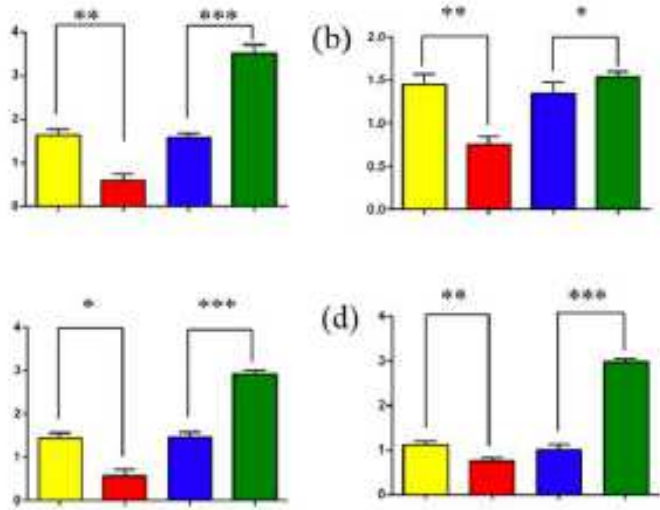

D.

- MEXsa
GAPDH

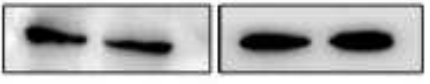

(D)

H1299
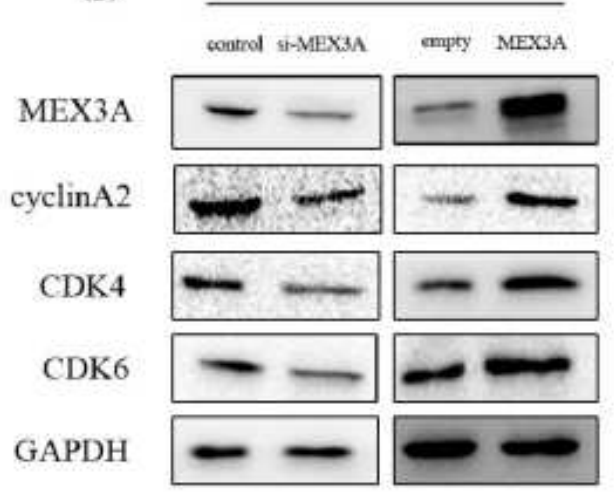

$55 \mathrm{kDa}$

$55 \mathrm{kDa}$

$34 \mathrm{kDa}$

$36 \mathrm{kDa}$

$36 \mathrm{kDa}$ (a)

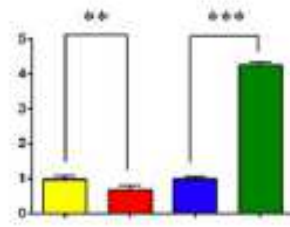

(c)

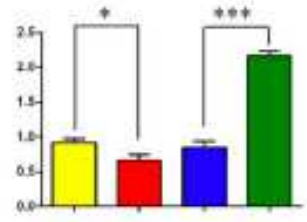

(d)

(b)

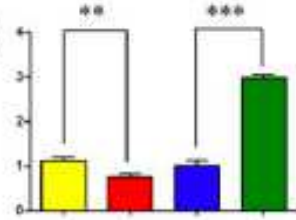

b)

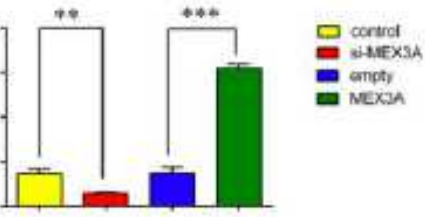

(d)

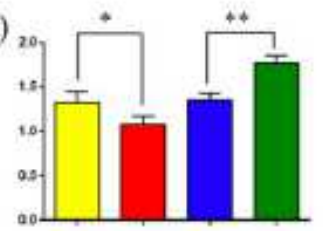

\section{Figure 4}

Effect of MEX3A expression on colony formation and proliferation of NSCLC cells. A549 and H1299 cells were transfected with MEX3A-specific siRNA (si-MEX3A) or control siRNA (control), or with a MEX3A expression plasmid (MEX3A) or vehicle (empty). ${ }^{*} P<0.05$, ${ }^{*} P<0.01$ and ${ }^{* \star *} P<0.001$. A. Colony formation assay. (a) A549: si-MEX3A vs control; MEX3A vs empty. (b) H1299: si-MEX3A vs control; MEX3A vs empty. B. MTT assay. (a) A549: si-MEX3A vs control; MEX3A vs empty. (b) H1299: si-MEX3A vs control; MEX3A vs empty. C, E. Changes in expression of cell proliferation-related proteins in (D) A549 and (E) H1299 cells. 


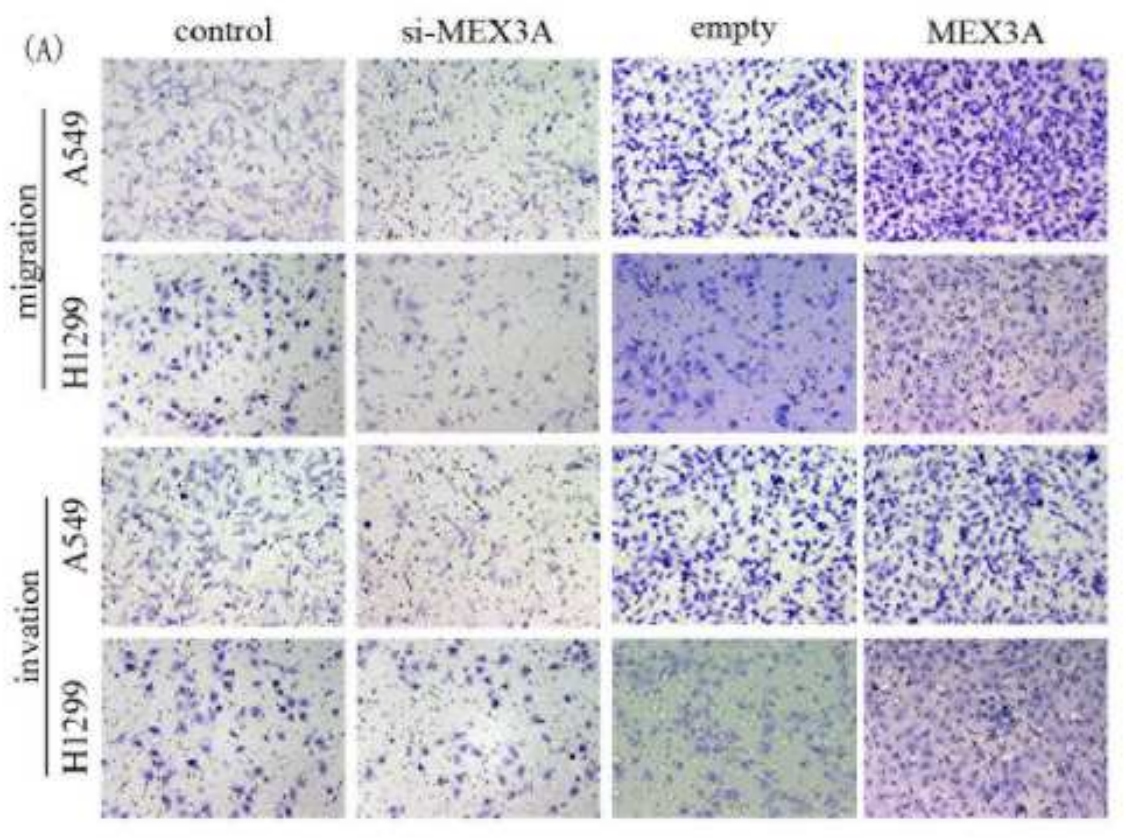

(a)

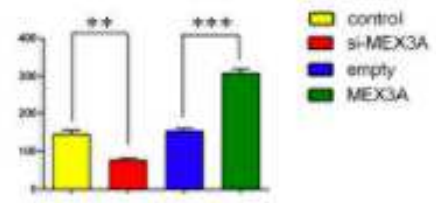

(b)

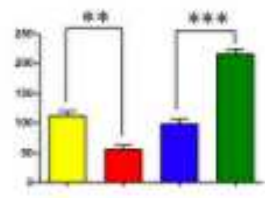

(c)

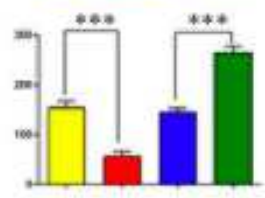

(d)

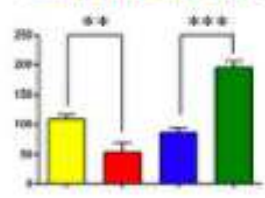

(B)

A549

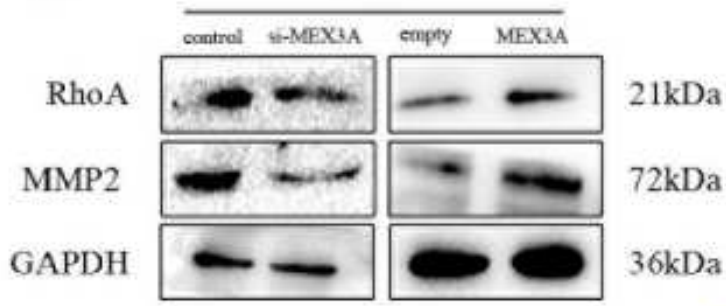

(a)

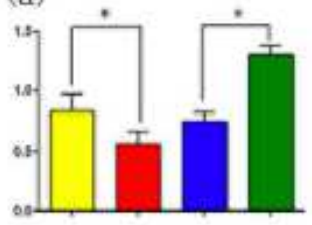

(c)

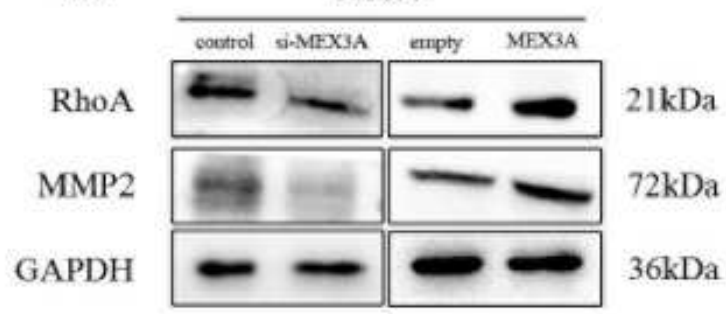

\section{Figure 6}

Effect of MEX3A expression on the migration and invasion of NSCLC cells. A549 and H1299 cells were transfected with MEX3A-specific siRNA (si-MEX3A) or control siRNA (control), or with a MEX3A expression plasmid (MEX3A) or vehicle (empty). ${ }^{\star} P<0.05$, ${ }^{\star *} P<0.01$ and ${ }^{\star} \star \star * P<0.001$. A. Cell migration as analyzed by a Transwell migration assay; cells that migrated to the lower chamber were stained with hematoxylin and counted. (a) A549 migration: si-MEX3A vs control; MEX3A vs empty. (b) H1299 migration: si-MEX3A vs control; MEX3A vs empty. (c) A549 invasion: si-MEX3A vs control; MEX3A vs empty. (d) H1299 invasion: si-MEX3A vs control; MEX3A vs empty. B,C. Expression of MEX3A and cell migration- and invasion-related proteins in transfected (B) A549 and (C) H1299 cells. 
(A)
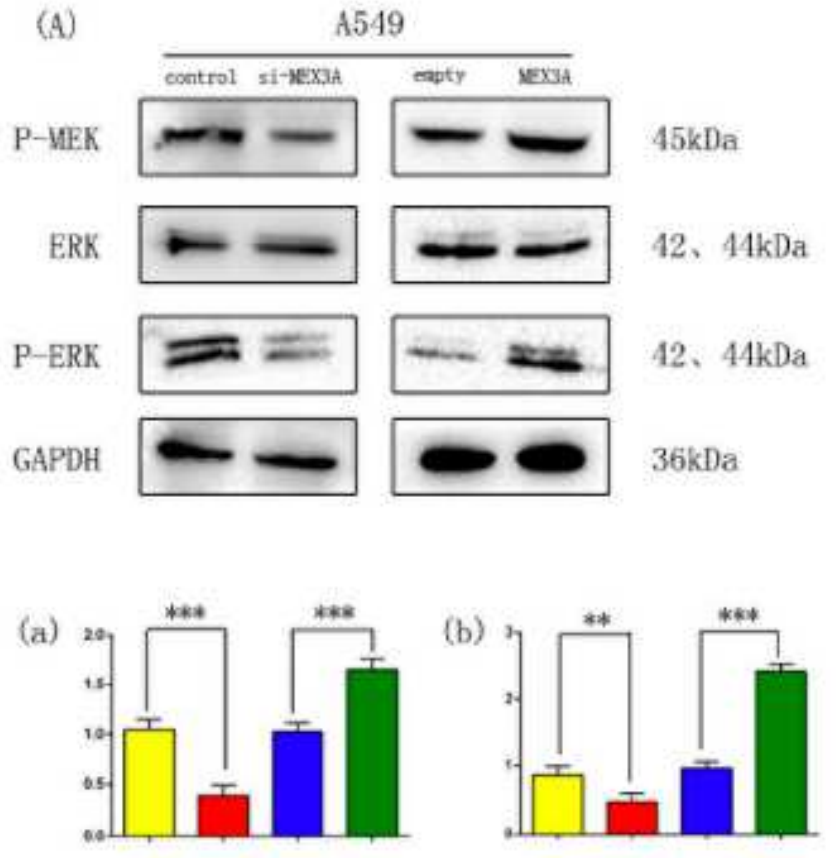

(b)

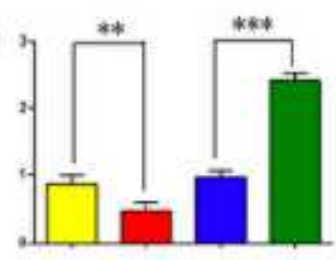

(B)

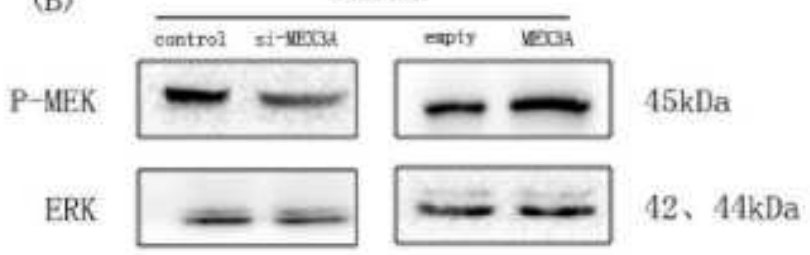

P-ERK

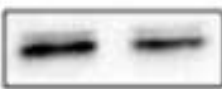

GAPDH
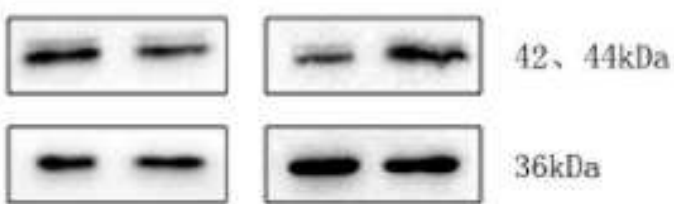

$36 \mathrm{kDa}$

\section{Figure 8}

Changes in the expression of MAPK-related proteins in (A) A549 and (B) H1299. Relative quantification analysis was based on grayscale values. ${ }^{*} P<0.05, * * P<0.01$ and $* * * P<0.001$. 

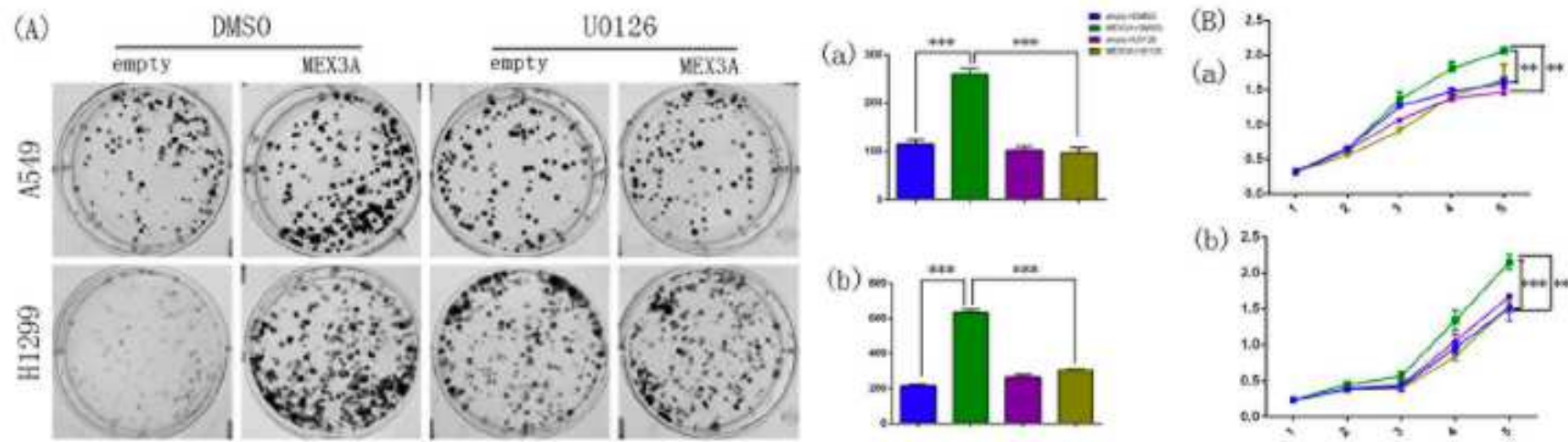

(b) 2

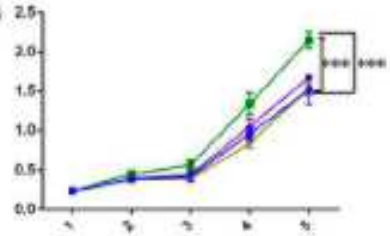

(c)
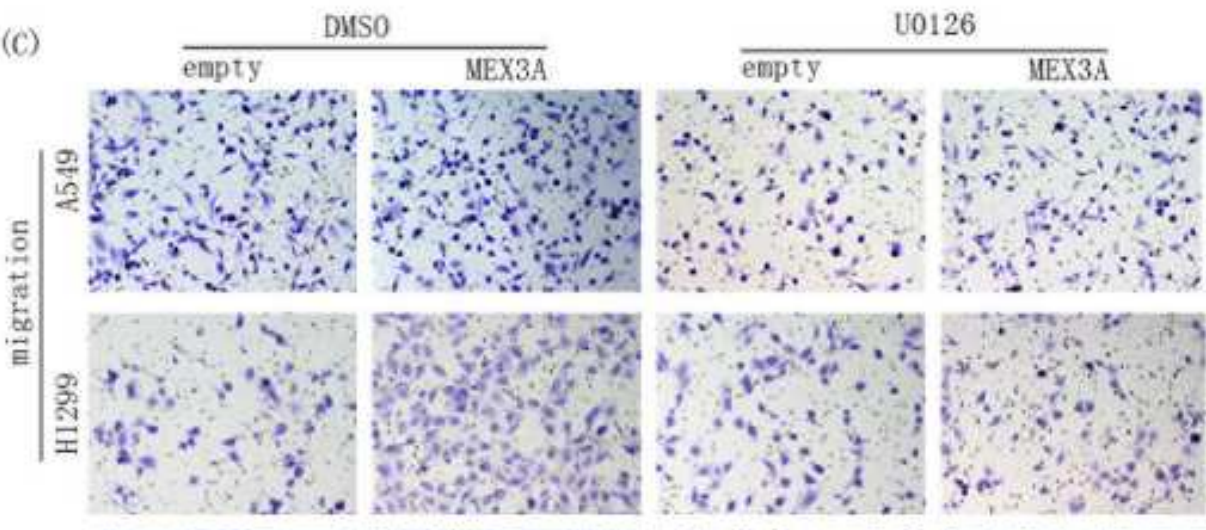

(a)
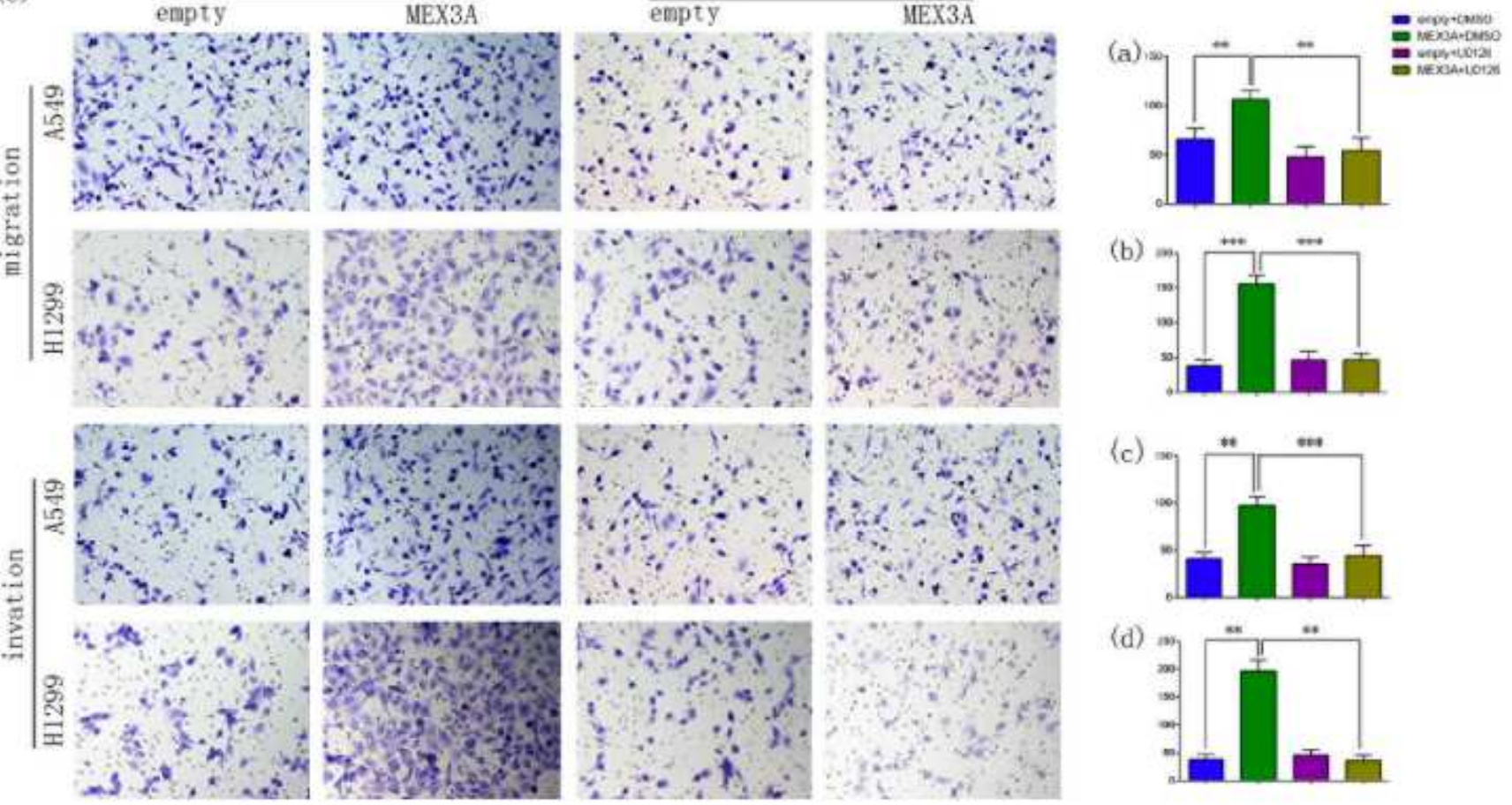

(b)

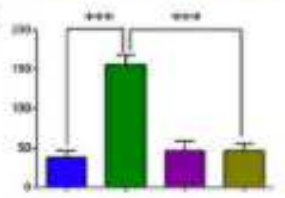

(c)

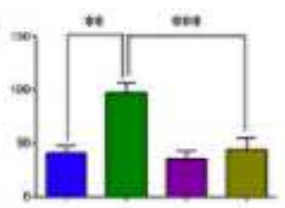

(d)

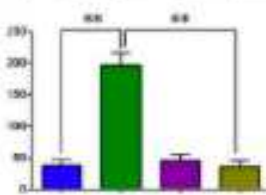

\section{Figure 10}

Effect of MEX3A with or without ERK inhibition on the behavior of NSCLC cells. A549 and H1299 cells transfected with a MEX3A expression plasmid were treated with the MEK inhibitor U0126 or DMSO (control) and analyzed for cell proliferation: (A) colony formation assay and (B) MTT assay; and (C) migration and invasion.

\section{Supplementary Files}

This is a list of supplementary files associated with this preprint. Click to download.

- Table2.xlsx 
- Table1.xIsx

- Table3.xlsx

- Table2.xlsx

- Table3.xlsx

- Table1.xlsx 